\title{
EDITORIAL
}

\section{Noninvasive monitoring of airway inflammation}

\author{
H. Magnussen*, F.E. Hargreave**
}

Airway inflammation plays an important role in diseases such as asthma and chronic bronchitis and is considered to be a major cause for exacerbations and persisting structural alterations of the airways. The assessment of airway inflammation is important for investigating underlying mechanisms of airway diseases. Furthermore, measurement of airway inflammation may reveal diseased airways not detectable by symptoms, lung function or airway hyperresponsiveness. Airway inflammation has been assessed in secretions and biopsies obtained during flexible bronchoscopy, but these methods are too invasive and not appropriate for monitoring airway inflammation repeatedly. In the past few years research has therefore focused on less invasive techniques such as the analysis of sputum and the evaluation of markers in exhaled air.

\section{Sputum}

The cellular and noncellular composition of sputum is a result of many biological processes occurring within the respiratory system and the analysis of sputum composition is therefore a valuable tool to study these processes. Sputum is thought to reflect the state of the more central airways, although, due to mucocilliary transport mechanisms and cell migration it is likely that sputum also consists of material which is derived from more peripheral areas of the lung.

As sputum examinations can be performed repeatedly it is also possible to investigate time courses of inflammatory processes. Examples are the acute neutrophilic inflammation after ozone exposure or the time course of eosinophilic inflammation after repeated low dose allergen provocations $[1,2]$. In contrast to granulocytes, macrophages have a longer life span, reside in the airways for much longer periods of time and are able to actively migrate. Processes like gastroesophageal reflux and left ventricular heart failure lead to an accumulation of lipids or haemosiderin within sputum macrophages, and the analysis of these markers in sputum macrophages has recently been suggested to be an indicator for these diseases [3, 4].

Sputum cytological examinations were already used at the end of the 19 th century, but later sputum examinations

\footnotetext{
*Krankenhaus Grosshansdorf, Zentrum für Pneumologie und Thoraxchirurgie, Grosshansdorf, Germany. **Firestone Regional Chest \& Allergy Unit, St. Joseph's Hospital-McMaster University, Hamilton, Canada.

Correspondence: H. Magnussen, Krankenhaus Grosshansdorf, Zentrum für Pneumologie und Thoraxchirurgie, D-22927 Grosshansdorf, Germany. Fax: 494102601245.
}

were mainly applied to the diagnosis of tuberculosis and to the early detection of lung neoplasms. The first method of sputum induction was described by BICKERMAN et al. [5] in 1958. After inhalation of nebulized hypertonic saline they were able to obtain sputum samples from patients that could not produce sputum spontaneously. The use of induced sputum for the analysis of airway inflammation in asthma was first described in 1992 and the work of PIN et al. [6] marked the beginning of a rapid spread of this method. The importance of sputum inductions for cell and molecular examination today is underlined by the formation of an European Respiratory Society Task Force, which aims at standardizing the method to further improve its future use.

\section{Exhaled air}

The main task of the respiratory system is the exchange of oxygen and carbon dioxide, but exhaled air also contains a large number of other volatile substances and the analysis of these compounds in human breath for the diagnosis of diseases has a long tradition in medicine. In the past few years research has mainly focused on nitric oxide (NO). Initially known as an environmental pollutant, NO has been identified as an important mediator with a wide spectrum of action.

The molecule NO originates from L-arginine which is converted to L-citrullin by NO-synthase (NOS), an enzyme, which exists in several isoforms. One of these isoforms can be induced by cytokines (inducible NOS) to produce large amounts of NO, which are very likely to be responsible for the finding that NO is elevated in exhaled air of asthmatic patients $[7,8]$. The enzyme can be inhibited by steroids and due to this the NO concentration in exhaled air decreases after steroid treatment, an effect that could possibly be used to monitor the compliance of patients. The measurement of NO in exhaled air is actually noninvasive, while the inhalation of hypertonic saline during sputum inductions still bares the risk of bronchoconstriction, and NO can be analysed with fast detectors which give immediate results. On the other hand, NO represents only an indirect measure of airway inflammation and requires expensive equipment. After a lot of debate about the correct method to measure NO, it was shown that the level of NO in exhaled air is flow dependent, indicating that it is derived from the central airways rather than from the alveoli [9].

The aim of the current series in the European Respiratory Journal is to summarize the recent developments in these rapidly progressing fields. It will cover both the 
methods of induced sputum examinations and the measurement of markers in exhaled air, which will mainly focus on NO. Both methods will be discussed from the methodological point-of-view and from their usefulness in clinical practice. This series is dedicated to the pneumologist interested in better understanding the methods used to measure cellular processes in the airways by noninvasive techniques.

The first paper of the series in this issue of the European Respiratory Journal will cover the usefulness of sputum examinations in clinical practice [10] and will be followed by an update on sputum methodology (Number 2). Numbers 3 and 4 of the series will then focus on measurements in exhaled air.

\section{References}

1. Holz O, Jörres RA, Timm P, et al. Ozone-induced airway inflammatory changes differ between subjects and are reproducible. Am J Respir Crit Care Med 1999; 159: 776784.

2. Sulakvelidze I, Inman MD, Rerecich T, O'Byrne PM. Increases in airway eosinophils and interleukin-5 with minimal bronchoconstriction during repeated low-dose allergen challenge in atopic asthmatics. Eur Respir $J$ 1998; 11: 821-827.

3. Parameswaran K, Anvari M, Efthimiadis A, Kamada D,
Hargreave FE, Allen CJ. Lipid-laden macrophages in induced sputum as a marker of oropharyngeal reflux and possible acid aspiration in gastro-esophageal reflux. Eur Respir J 2000; (in press).

4. Leigh R, Sharon R, Efthimiadis A, Kamada D, Hargreave FE, Kitching AD. Diagnosis of left ventricular dysfunction from induced sputum examination. Lancet 1999; 354: 833-834.

5. Bickerman HA, Sproul EE, Barach AL. An aerosol method of producing bronchial secretions in human subjects: a clinical technique for the detection of lung cancer. Dis Chest 1958; 33: 347-362.

6. Pin I, Gibson PG, Kolendowicz R, et al. Use of induced sputum cell counts to investigate airway inflammation in asthma. Thorax 1992; 47: 25-29.

7. Alving K, Weitzberg E, Lundberg JM. Increased amount of nitric oxide in exhaled air of asthmatics. Eur Respir $J$ 1993; 6: 1368-1370.

8. Kharitonov SA, Yates D, Robbins RA, Logan-Sinclair R, Shinebourne EA, Barnes PJ. Increased nitric oxide in exhaled air of asthmatic patients. Lancet 1994; 343: $133-$ 135.

9. Silkoff PE, McClean PA, Slutsky AS, et al. Marked flowdependence of exhaled nitric oxide using a new technique to exclude nasal nitric oxide. Am J Respir Crit Care Med 1997; 155: 260-267.

10. Jayaram L, Parameswaran K, Sears MR, Hargreave FE. Induced sputum cell counts: their usefulness in clinical practice. Eur Respir J 2000; 16: 150-158. 